\title{
Influence of Multiple Environmental Factors on Organic Matter Chlorination in Podsol Soil
}

Teresia Svensson, Malin Montelius, Malin Andersson, Cecilia Lindberg, Henrik

Reyier, Karolina Rietz, Åsa Danielsson and David Bastviken

The self-archived postprint version of this journal article is available at Linköping University Institutional Repository (DiVA):

http:/ / urn.kb.se/ resolve?urn=urn:nbn:se:liu:diva-144266

N.B.: When citing this work, cite the original publication.

Svensson, T., Montelius, M., Andersson, M., Lindberg, C., Reyier, H., Rietz, K., Danielsson, Å.,

Bastviken, D., (2017), Influence of Multiple Environmental Factors on Organic Matter Chlorination in Podsol Soil, Environmental Science and Technology, 51(24), 14114-14123.

https:// doi.org/ 10.1021/ acs.est.7b03196

Original publication available at:

https:// doi.org/ 10.1021/acs.est.7b03196

Copyright: American Chemical Society

http:// pubs.acs.org/ 


\section{Influence of multiple environmental factors on}

\section{organic matter chlorination in podsol soil}

Teresia Svensson*, Malin Montelius, Malin Andersson, Cecilia Lindberg, Henrik Reyier, Karolina Rietz, Åsa Danielsson, David Bastviken

Linköping University, Department of Thematic Studies, Environmental Change, SE-581 83 Linköping, Sweden

Keywords: chlorination, organic chlorine, soil organic matter, soil moisture, chloride, nitrogen

\section{Abstract}

Natural chlorination of organic matter is common in soils. The abundance of chlorinated organic compounds frequently exceeds chloride in surface soils, and the ability to chlorinate soil organic matter (SOM) appears widespread among microorganisms. Yet, the environmental control of chlorination is unclear. Laboratory incubations with ${ }^{36} \mathrm{Cl}$ as a $\mathrm{Cl}$ tracer were performed to test how combinations of environmental factors, including levels of soil moisture, nitrate, chloride, and labile organic carbon, influenced chlorination of SOM from a boreal forest. Total chlorination was hampered by addition of nitrate or by nitrate in combination with water, but enhanced by addition of chloride or most additions including labile organic matter (glucose and maltose). The greatest chlorination was observed after 15 days when nitrate and water were added together with labile organic matter. The effect that labile organic matter strongly stimulated the chlorination rates was confirmed by a second 
independent experiment showing higher stimulation at increased availability of labile organic matter. Our results highlight cause-effect links between chlorination and the studied environmental variables in podsol soil - with consistent stimulation by labile organic matter that did overrule the negative effects of nitrate.

\section{Introduction}

The abundance of naturally formed chlorinated organic compounds $\left(\mathrm{Cl}_{\text {org }}\right)$ in soil frequently exceeds the abundance of chloride $\left(\mathrm{Cl}^{-}\right)$, particularly in boreal forest soils ${ }^{1,2}$. This large pool of organic chlorine is a consequence of chlorination processes (i.e. the processes by which $\mathrm{Cl}$ atoms are covalently bound to soil organic matter; SOM). Previous studies indicate that substantial chlorination of organic matter can occur in all types of soils ranging from agricultural to forest soils ${ }^{3}$. Two general types of chlorination processes have been described, including intracellular formation of specific chlorinated compounds under halogenase enzyme control, and non-specific extracellular chlorination following formation of reactive chlorine by chloroperoxidase enzymes (CPO) and interactions between the reactive chlorine and surrounding organic matter ${ }^{4,5}$. Most of the chlorination is probably biotic being regulated directly or indirectly by enzymes ${ }^{6}$, but chlorination linked to redox cycling of iron without direct biotic influence has also been shown ${ }^{7,8}$.

The extensive natural chlorination of organic matter in soil suggest that the turn-over of organic chlorine are most likely linked to common ecosystem processes such as microbial activity, but the fundamental reasons for the chlorination is still unclear. Several alternatives have been hypothesized including:

1. Chlorination can be a part of allelopathic processes, e.g. defense against pathogens/competitors/parasites, and could represent a way for plant parasites to break through host cell walls ${ }^{9}$. The organisms using CPO produce reactive chlorine (e.g. 
hypochlorous acid, $\mathrm{HOCl}$ ), which have biocidal and biostatic effects known to be important for some cellular defense mechanisms ${ }^{10,11}$.

2. The formation of $\mathrm{HOCl}$ could be a defense against reactive oxygen species that are formed as by-products in cellular metabolism ${ }^{12}$. CPO catalyzes reactions between hydrogen peroxide $\left(\mathrm{H}_{2} \mathrm{O}_{2}\right.$; one of the most abundant reactive oxygen species generally formed in oxic metabolism) and $\mathrm{Cl}^{-}$, generating $\mathrm{HOCl}$. The produced $\mathrm{HOCl}$ can react with surrounding organic matter and thereby reduce oxidative stress.

3. Biotic chlorination could be a way for microorganisms to access refractory organic matter $^{13,14}$. CPO and other haloperoxidases in the terrestrial environment seem to originate from organisms associated with plants or decomposing plant material ${ }^{9}$. HOCl acid can break C-C bonds in complex and refractory organic compounds, as shown by e.g. Ortiz-Bermu'dez et al (2003) ${ }^{15}$, who observed that chlorination and cleavage of a lignin model dimer was enhanced by addition of CPO.

There is evidence in support of all of these hypotheses but their relative importance in soil is unclear. Chlorination rates (i.e., the amount of $\mathrm{Cl}^{-}$that is covalently bound to organic matter per time unit) under various environmental conditions can potentially provide insights in how chlorination is regulated and the balance between chlorination and dechlorination processes. Dechlorination of bulk SOM is less studied than chlorination, but occur at high rates in soils ${ }^{16}$, and can include reductive removal of covalently bound $\mathrm{Cl}$ from SOM by e.g. halorespiration ${ }^{17}$ or release of organically bound $\mathrm{Cl}$ upon SOM mineralization. The balance between chlorination and dechlorination can be expressed as the net chlorination. A reported seasonal pattern, with increase in aromatic chlorinated organic compounds during summer months and decrease during winter months, in decaying plant material study suggests increased net chlorination activity during summer months than during the colder period of the year $^{18}$. Net-chlorination rates have already been shown to increase with temperature 
following the characteristic enzyme-type temperature response ${ }^{6}$. Recently, it was also found that the type of dominant tree species in forest stands has profound impact on overall $\mathrm{Cl}$ and $\mathrm{Cl}_{\text {org }}$ levels showing that biological factors are important for net chlorination ${ }^{19}$. From experimental studies (as opposed to field observations), it has been proposed that net chlorination rates are i) stimulated by a high level of organic matter content ${ }^{3}$, ii) hampered by anoxic conditions $^{6}$, and iii) possibly affected by soil nitrogen (both inhibition of chlorination at elevated nitrogen levels and no clear effects of nitrogen have been reported) ${ }^{1,16,20,21}$. The relative importance and potential interaction effects of the different environmental factors will thus improve our understanding of regulation of SOM chlorination.

The aim of the study was first to investigate the single and combined effects of a set of environmental variables, including soil moisture $(\mathrm{W})$, nitrate $\left(\mathrm{NO}_{3}-\mathrm{N}\right)$, chloride $(\mathrm{Cl})$ as well as the lability of the organic carbon source (C). Secondly, we performed a more detailed investigation of how organic matter lability influences chlorination of SOM. Both experiments focused on podsol soil because this soil type has exhibited extensive chlorine cycling in past studies ${ }^{19}$ and is very common in the boreal biome.

\section{Experimental setup and methods}

In order to analyze how environmental factors influence chlorination of SOM we conducted two laboratory experiments. The first (Experiment I) was a factorial study to test for combined effects of different environmental factors, and the second (Experiment II) focused on the impact of adding different $C$ sources. In both experiments, a known amount of the radioactive tracer ${ }^{36} \mathrm{Cl}^{-}$was added to soil that was incubated under controlled conditions for temperature, humidity and aeration. The incorporation of ${ }^{36} \mathrm{Cl}$ to the soil organic matter was measured in the different treatments. 


\section{Experiment I}

Soil sampling

Soil was collected from a spruce forest at one of the sites of the Swedish long-term soil monitoring network $\left(57^{\circ} 52^{\prime} \mathrm{N}, 15^{\circ} 49^{\prime} \mathrm{E}\right)$. The litter layer was removed and the samples were collected from 5-15 cm depth representing the A-horizon, and transported to the Linköping University laboratory in polyethylene bags. To make the soil homogeneous and remove large roots, the fresh soil was sieved through a $2 \mathrm{~mm}$ mesh before storage at $4^{\circ} \mathrm{C}$. The soil was stored during a period of 18 months to deplete easily degradable organic matter and thereby make it easier to detect potential effects of additions of labile organic matter on chlorination. The storage also allowed time for recovery and stabilization after the disturbance caused by the sieving.

\section{Experimental set up}

A full factorial design was used to study combination effects of different treatments. Four different variables/factors were chosen: soil moisture (hereafter denoted as W); sodium nitrate $\left(\mathrm{NaNO}_{3}\right.$; hereafter denoted as $\left.\mathrm{NO}_{3}-\mathrm{N}\right)$; labile carbon (glucose and maltose; hereafter denoted as $\mathrm{C})$; and sodium chloride ( $\mathrm{NaCl}$; hereafter denoted as $\mathrm{Cl})$. We used two levels, addition (+) and no addition (-) to the stored soil, for each of the four factors. The specific additions of each factor in the $(+)$ treatments were selected to considerably increase the levels compared to the natural levels, while still maintaining levels which could be realistic in soils under certain conditions ${ }^{1,22}$. The amounts of added $\mathrm{NO}_{3}-\mathrm{N}\left(\right.$ as $\left.\mathrm{NaNO}_{3}\right)$ were 20 times as high as the original levels and represented $\mathrm{N}$ additions commonly used for fertilization in Swedish forestry. $\mathrm{NaCl}$ additions were 10 times as high as the original levels representing coastal conditions as well as situations during dry periods when soil pore water ionic strength is high. In the $\mathrm{W}(+)$ treatment, the water saturation was doubled from $36 \%$ to $70 \%$. Glucose and maltose are easily degradable sources of carbon (C), and were added in equal proportions and the total addition corresponding to a $20 \%$ increase of total C compared to the original levels in the soil. The glucose and maltose were added in dry form and were then thoroughly mixed 
with the soil upon isotope addition (see below). One of the treatments had no additions and was used as control.

Since there are four factors tested in different combinations, there are 16 possible combinations of factors (Table 1). For each treatment (e.g. combination of factors) six separate replicate samples were incubated; three of which were incubated for 15 days and three of which were incubated for 60 days. The selection of these sampling times was based on previous work illustrating that during the first phase of this type of tracer experiments, gross chlorination could be determined from the increase of ${ }^{36} \mathrm{Cl}_{\text {org }}$ after the initial addition of ${ }^{36} \mathrm{Cl}^{16}$. Later, the results rather reflect a net-chlorination with simultaneous chlorination and dechlorination. Hence, 15-day samples are assumed to reflect gross chlorination of the different combinations, while 60 day-samples are more representative of net chlorination.

\section{Experiment II}

Soil sampling

Soil was collected from podsol soil in a coniferous forest dominated by Norway spruce (Picea abies) and Scots pine (Pinus sylvestris) $\left(58^{\circ} 44^{\prime} \mathrm{N}, 16^{\circ} 21^{\prime} \mathrm{E}\right)$. Samples were taken from the A horizon and transported in plastic bags (polyethylene) to the laboratory. The soil was sieved (2 mm mesh, as for Experiment I) and stored at $4^{\circ} \mathrm{C}$, dark, under aerobic conditions for 2.5 years before the experiment start, to deplete the most labile organic matter.

\section{Experimental setup}

This experiment was setup to test if chlorination was affected by the presence of carbon sources having different lability (i.e. being differently accessible to microorganisms) (Table 2). Experiment II had the same basic experimental design as Experiment I. This experiment was run for 140 days with samplings $(n=3)$ on day $0,9,37,64,112,140$ to reveal differences in both net and gross chlorination ${ }^{18}$.

The soil without any additions served as a control treatment with SOM assumed to be least labile (with respect to microbial degradation). Three additional treatment with gradually 
increased SOM lability were created by the addition of sawdust from Norwegian spruce wood (SWD), starch, plus cellulose (SC), and a mixture of glucose, maltose, starch and cellulose (GMSC; equal proportions in terms of carbon content). The total addition corresponded to approximately $20 \%$ of the initial organic carbon content (as in the Experiment I described above).

\section{Soil incubations and extractions}

Soil incubation. In both experiments, $2 \mathrm{~g}$ soil (fresh weight) was transferred to test tubes (50 ml, Sarstedt, Germany). Thereafter, additions of $\mathrm{NaNO}_{3}, \mathrm{NaCl}$, and organic $\mathrm{C}$ was made according to the treatments described above. Finally, $\mathrm{Na}^{36} \mathrm{Cl}$ was added in a water solution (Amersham Biotech; 0,59MBq / mg Cl) so that each tube contained 105,000 disintegrations per minute (dpm; standard deviation=129 dpm, n=3) for Experiment I and 153,000 dpm (standard deviation=1,047 dpm, $\mathrm{n}=3$ ) for Experiment II I. 1Bq equals $60 \mathrm{dpm}$. The total volume of added solution (including $\mathrm{Na}^{36} \mathrm{Cl}$ solution and the additions) was $0.9 \mathrm{~mL}$ per tube, an amount sufficient to make the soil semi fluid for easy mixing to distribute all additions homogeneously in the soil. The solution added a mass of $7.2 \mu \mathrm{g}$ of $\mathrm{Cl}^{-}$per test tube. After adding ${ }^{36} \mathrm{Cl}^{-}$solution, the samples were dried under a fan at room temperature to reach the original fresh weight, except for the $\mathrm{W}$ treatment where the water content were kept higher (at 70\%; see text about treatment).

To minimize water loss while maintaining aerobic conditions, a pump system similar to that described by Bastviken et al (2007) $)^{23}$ was used. Briefly, ambient air was pumped via two test tubes with water connected in a sequence (the air being purged through the water to increase its humidity) and then to each single experiment tube separately. This enables moist air to flow through the samples, maintaining a constant moisture level (confirmed by weekly weighing of the tubes). The system was controlled by a timer, and moist air was pumped through the test tube for 15 minutes, every fourth hour. The incubations were made at room temperature $\left(20^{\circ} \mathrm{C}\right)$. The incubation periods were stopped by freezing the soil tube replicates 
from all treatments $\left(-20^{\circ} \mathrm{C}\right)$ on day 15 and 60 for Experiment I, and day 9, 37, 64, 112, and 140 for Experiment II. The samples remained frozen until extracted and analyzed further.

Extractions. The extractable $\mathrm{Cl}$ was separated from the non-extractable $\mathrm{Cl}$ and thus give us an estimate of the soil phase-bound $\mathrm{Cl}_{\text {org }}{ }^{19,23}$. First, each sample was thawed, after which 20 $\mathrm{ml}$ of Milli-Q water was added to each sample. The samples were then put in a shaker for 30 minutes followed by centrifugation (10 minute, RCF 5313). Each supernatant was transferred from the sample to a new vial. The soil samples were then dried $12-18 \mathrm{~h}$, at $60^{\circ} \mathrm{C}$. After drying each sample was ground with a mortar, followed by an addition of $5 \mathrm{ml}$ Milli-Q water and sonication with an ultrasonic probe, for 45 seconds at an intensity of 50\% (Bandelin sonopuls, UW2070; the combination of freezing, drying and sonication was designed to disrupt cells to release intracellular $\left.\mathrm{Cl}^{-}\right)^{23}$. Another $15 \mathrm{ml}$ of Milli-Q water was added to each sample and the 30 min shaking followed by centrifugation as described above. The supernatant was transferred to a new vial using a pipette. Subsequently, $20 \mathrm{ml}$ of $0.01 \mathrm{~mol} \mathrm{~L}^{-1}$ $\mathrm{KCl}$ was added to each sample followed by extraction in the shaker for 30 minutes and centrifugation as above. The supernatant from each sample was extracted to new individual vials. The same extraction procedure was repeated once more yielding a fourth extract. Then the extracted soil samples were again dried at $60^{\circ} \mathrm{C}$ overnight and frozen until further analysis. The mass of each extract and residual soil were measured between each step throughout the whole extraction procedure.

\section{Analysis of soil characteristics}

The original soils used in both experiments (approximately $2 \mathrm{~g}$ ) were dried in an oven at $105^{\circ} \mathrm{C}$ to a constant weight and the soil moisture content was calculated $(\mathrm{n}=3)$. Loss-onIgnition (LOI; the loss of weight during combustion) was determined by combustion at $620^{\circ} \mathrm{C}$ for two hours. The amount of organic carbon was assumed to be $50 \%$ of the weight loss $(n=3)$, with negligible amount of carbonates. Water extracts of the original soils were used for $\mathrm{pH}$ analysis $(\mathrm{n}=3)$. Parts of the original soils was also dried and milled, and analyzed for total 
organic halogens (TOX) and total halogens (TX) according to Asplund et al (1996) ${ }^{24}$ using an ECS3000 analyzer (Euroglas). The chloride concentrations were estimated by subtracting TOX from TX.

Analysis of ${ }^{36} \mathrm{Cl}$ org formation in the residual soil

A modified total halogens (TX) method was used to analyze total soil bound organic ${ }^{36} \mathrm{Cl}$ chlorine $\left({ }^{36} \mathrm{Cl}_{\text {org }}\right.$ ) according to the principle that ${ }^{36} \mathrm{Cl}_{\text {org }}$ converted to $\mathrm{H}^{36} \mathrm{Cl}$ by combustion and purging through $\mathrm{H}_{2} \mathrm{SO}_{4}$, was trapped in $\mathrm{NaOH}$ and analyzed by liquid scintillation counting 23. Approximately $0.2 \mathrm{~g}$ of soil from each sample was used for the incineration (exact mass \pm 0.001 used in later calculations). The soil was weighed in a small ceramic cup, which was then placed in the "sample boat" part of the AOX instrument (Euroglas). The boat was gently pushed into the oven, which was preheated to $1000^{\circ} \mathrm{C}$ having an atmosphere of $\mathrm{O}_{2}$. One sample at the time was incinerated during 20 minutes. The incineration process transforms all $\mathrm{Cl}$ to $\mathrm{HCl}$ or $\mathrm{Cl}_{2}$. The gas is bubbled through sulfuric acid to convert the $\mathrm{Cl}_{2}$ to $\mathrm{HCl}$, and then the $\mathrm{HCl}$ is trapped when purged through $2 \mathrm{x} 10 \mathrm{ml}$ of $0.1 \mathrm{M}$ sodium hydroxide ( $\mathrm{NaOH}$ : two scintillation vials connected in series; $>98 \%$ trapped $)^{23,25}$. The vials containing the captured ${ }^{36} \mathrm{Cl}$ from the incineration received an addition of $10 \mathrm{ml}$ of scintillation cocktail (Ultima Gold $\mathrm{XR}$, Chemical Instruments $\mathrm{AB}$; emitting luminescence in proportion to the radioactivity, allowing detection in a liquid scintillation counter) and were manually shaken. The samples were analyzed together with blank samples. The liquid scintillation counter (Beckman LX 6300) contains a photo detector and converts the measured luminescence to dpm, with

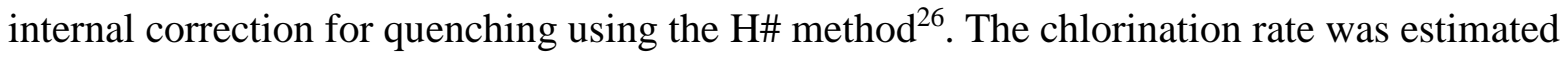
by multiplying the percentage of ${ }^{36} \mathrm{Cl}$ incorporated into the SOM with the total $\mathrm{Cl}^{-}$ concentration in original soil. 


\section{Statistics}

To test if there were significant differences in Experiment I between control, treatments and interaction effects, the non-parametric test Kruskal-Wallis and the post hoc pairwise test (Tukey) were used. The significance level was set to 0.05. A The Mann-Whitney U test was used to test the significance of differences $(p<0.05)$ between the control and the different treatments with gradually increased SOM lability.

\section{Results}

\section{Soil characteristics}

The soil water content by mass was similar (average 36.4\% and 32.7\%, respectively) for the soils in Experiment I and II. The average soil organic carbon content was $84 \mathrm{mg} \mathrm{C}_{\text {org }} \mathrm{gdm}_{\mathrm{dm}}{ }^{-}$ ${ }^{1}$ (gdm denoting gram dry mass) for Experiment I and slightly higher in Experiment II (101 mg $C_{o r g} g_{d_{m}}{ }^{-1}$ ). The average chloride levels were similar with $102.2 \mu \mathrm{g} \mathrm{Cl}^{-} \mathrm{g}_{\mathrm{dm}}{ }^{-1}$ and 107.4 $\mu \mathrm{g} \mathrm{Cl}^{-} \mathrm{g}_{\mathrm{dm}}{ }^{-1}$, respectively, for soils from Experiment I and II. In Experiment I soils, the original nitrogen content was $0.64 \%$ and $\mathrm{pH}$ was approximately $4.7\left(\mathrm{pH}_{\mathrm{H} 2 \mathrm{O}}\right)$.

Formation of $\mathrm{Cl}_{\text {org }}$

Experiment I

The chlorination of organic matter in the control samples, ranged from 14.2-21.1 ng Cl $\mathrm{gdm}^{-1} \mathrm{~d}^{-1}$ at day 15 and 9.9 to $10.0 \mathrm{ng} \mathrm{Cl} \mathrm{gdm}{ }^{-1} \mathrm{~d}^{-1}$ at day 60 (Figure 1). These control levels of ${ }^{36} \mathrm{Cl}_{\text {org }}$ formation are used as references values when describing positive and negative effects of treatments below.

\section{Single factor treatments}

Until day 15 (i.e. the first period best reflecting gross chlorination rates) the $\mathrm{N}$ treatment had clearly reduced chlorination rates - approximately 25\% of the control levels- suggesting that high $\mathrm{NO}_{3}-\mathrm{N}$ levels had a negative effect on the gross-chlorination rate (Table 2). Soil samples incubated with increased soil moisture (W) had similar chlorination rate as the 
control (Table 2). The addition of $\mathrm{C}$ (as glucose/maltose) and $\mathrm{Cl}^{-}$increased the gross chlorination rate almost three-fold relative to controls.

After 60 days of incubation (when net chlorination rate rather than gross chlorination was reflected), the inhibitory effect in the $\mathrm{N}$ treatment was even stronger than for day 15 (Table 2). Increased soil moisture (W) did not show any clear deviation from the control samples and therefore did not seem to have any effect on the chlorination at either day 15 or day 60 . The highest chlorination was again found in the $\mathrm{C}$ and $\mathrm{Cl}$ treatments, with ${ }^{36} \mathrm{Cl}_{\text {org }}$ levels reaching approximately $15.5 \mathrm{ng} \mathrm{Cl} \mathrm{gdm}{ }^{-1} \mathrm{~d}^{-1}$ for $\mathrm{C}$ and $19.4 \mathrm{ng} \mathrm{Cl} \mathrm{gdm}{ }^{-1} \mathrm{~d}^{-1}$ for $\mathrm{Cl}$, of the added ${ }^{36} \mathrm{Cl}$ which was about 1.5 to 2 -fold the control at day 60 (Table 2).

\section{Combinations of factors}

The effects of the combination treatments were similar at both 15 and 60 days (Figure 2). Two combination of treatments are significant different from each other; WN and WNC treatments (Kruskal-Wallis, $p=0.017$ ) as well as N and WNC treatments (Kruskal-Walis, $p=0.019$ ) at day 15. At day 60, no significant differences could be found. The general pattern of the treatments were as follows (Figure 2).

Negative effects on chlorination:

- The combination $\mathrm{W}+\mathrm{N}+$ hampered chlorination rates at both times (rates ranged between $24 \%$ at day 15 and $14 \%$ at day 60 of the control rates).

- The combination $\mathrm{W}+\mathrm{N}+\mathrm{Cl}$ had a chlorination range that overlapped with control rates at day 15 but were slightly below the control range at day 60 .

Positive effects on chlorination:

- All combinations with $\mathrm{C}+$ increased chlorination rates (the full range of all replicate measurements of the treatments was separate and higher than the full range of the control replicates). 
- The $\mathrm{W}+\mathrm{N}+\mathrm{C}+$ treatment showed the most enhanced chlorination rates relative to the control treatment (eight-fold higher) at day 15 and still had a higher chlorination rate than control treatments at day 60, although lower than at day 15.

- The $\mathrm{W}+\mathrm{C}+$ treatment increased chlorination rates moderately relative to the control treatment (three-fold higher) at day 15 but less at day 60 (two-fold higher).

- The $\mathrm{N}+\mathrm{C}+$ treatment had similar chlorination rate as the control treatment until day 15, but showed higher chlorination rate until day 60 .

- All combinations including $\mathrm{Cl}+$ and $\mathrm{C}+$ usually led to higher chlorination than in the control treatment, and more clearly so at day 60 .

Hence, the overall results were that the $\mathrm{C}+$ treatment and $\mathrm{Cl}+$ in some combinations was a strong stimulator of chlorination rates. These overall effects were then modulated in combination by additional factors (see discussion).

\section{Experiment II}

The addition of labile organic matter was one of the most important factors enhancing netchlorination rates in Experiment I. Experiment II focused entirely on the effects of organic matter and confirmed that the organic matter lability have large effects on the incorporation of ${ }^{36} \mathrm{Cl}$ into soil organic matter. Already at day 9 (the first sampling) the treatment with glucose and maltose addition (GMSC) had much higher ${ }^{36} \mathrm{Cl}_{\text {org }}$ levels, corresponding to a median chlorination rate of (488 $\mathrm{ng} \mathrm{Cl} \mathrm{gdm}{ }^{-1} \mathrm{~d}^{-1}, \sim 38 \%$ of the added ${ }^{36} \mathrm{Cl}$ ), compared to the other treatments in which $<10 \%\left(<110 \mathrm{ng} \mathrm{Cl} \mathrm{gdm}{ }^{-1} \mathrm{~d}^{-1}\right)$ of the added ${ }^{36} \mathrm{Cl}$ had been converted to ${ }^{36} \mathrm{Cl}_{\text {org }}$ at this time (Figure 3). Thereafter, at day 37 and 64, there was a slight differentiation among the treatments where the chlorination were progressively higher in treatments with additions of more labile organic matter. At day 64, the median (min-max) net chlorination rates were 57 (49-65), 71 (65-73), 86 (81-86) ng Cl g $\mathrm{dm}^{-1} \mathrm{~d}^{-1}$ for sawdust (SWD), starch and cellulose (SC), and the GMSC treatment, respectively which was clearly higher than the control 46 (34-47) ng Cl gdm ${ }^{-1} \mathrm{~d}^{-1}$. After five months or longer, the median net 
chlorination rate of the control corresponded to $24(24,0-24,4) n g \mathrm{Cl} \mathrm{g}_{\mathrm{dm}}{ }^{-1} \mathrm{~d}^{-1}$, while the SWD and SC treatment rates were approximately 32 (28-41) and 37 (36-40) ng Cl gdm ${ }^{-1} \mathrm{~d}^{-}$ ${ }^{1}$ with higher variation among replicates than earlier in the experiment. The GMSC treatment reached the highest median net chlorination rate of all treatments (47 $\mathrm{ng} \mathrm{Cl} \mathrm{gdm}{ }^{-1} \mathrm{~d}^{-1}$ ranging

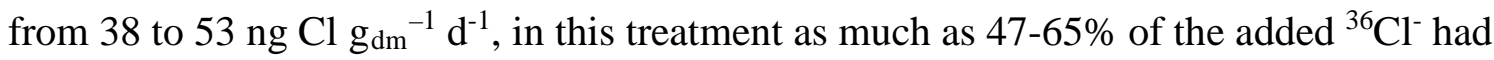
been transformed to ${ }^{36} \mathrm{Cl}_{\text {org }}$ at this time) (Figure 3). Hence, while the GMSC treatment stood out against all other treatments at day 9 (reflecting gross chlorination rates) and had highest level of ${ }^{36} \mathrm{Cl}_{\text {org }}$ being formed, the differences between all treatments with carbon addition diminished over time. However, the control had significantly lower ${ }^{36} \mathrm{Cl}_{\text {org }}$ levels and formation rates than the carbon addition treatments throughout the whole experiment (SWD treatment: $\mathrm{p}=0.044$, GMSC treatment: $\mathrm{p}<0.001$, SC treatment: $\mathrm{p}=0.008$ ).

\section{Discussion}

Both experiments showed chlorination at similar rates as observed in previously published studies, ranging from 5 to $90 \mathrm{ng} \mathrm{Cl} \mathrm{g \textrm {dm } ^ { - 1 } \mathrm { d } ^ { - 1 } \text { over } 6 0 \text { days }}{ }^{3,6}$. Chlorination rates were strongly affected by all studied environmental factors accept soil moisture alone. Two major effects were observed: (1) Addition of labile organic matter increased chlorination rates both alone and in combination with elevated soil moisture, chloride and nitrate levels (Table 2 and Figure 2), and (2) chlorination rates were reduced in all treatments with nitrate only (Figure 2).

\section{Addition of organic carbon increased chlorination rates}

The fundamental result that increased availability of labile organic matter increased the $\mathrm{Cl}_{\text {org }}$ formation rates was shown in both experiments, with more detailed results regarding effects of different types of organic matter over time in Experiment II. Glucose and maltose represent easily available carbon compounds that can be directly taken up and used by microorganisms, while degradation of less labile organic compounds, such as cellulose, 
require exoenzymatic degradation prior to microbial uptake ${ }^{27}$. In our closed experimental systems, it seems like addition of organic matter in mixtures with different lability, from saw dust, cellulose, starch, glucose and maltose, all had positive effects on how much $\mathrm{Cl}_{\text {org }}$ was formed over 5 months or longer (Figure 3). Apparently, any addition of these compounds was favorable to chlorination compared to the stored soil. Addition of cellulose together with starch in Experiment II yielded approximately 10\% lower chlorination than the addition of all carbon sources (glucose, maltose, starch and cellulose) in the later part of Experiment II. The sawdust coming from spruce wood is less well defined but primarily consists of cellulose and lignin - the latter being more complex to degrade than cellulose as lignin degradation is primarily based on degradation by extracellular oxidative enzymes such as different types of heme-containing peroxidases ${ }^{28}$. Sawdust resulted in a small but still clear increase in the chlorination rates compared to the control soil being aged for $>2$ years. Hence, Experiment II showed a progressive effect of the SOM lability, i.e. more labile organic matter yields more strongly stimulated chlorination rates. However, the initial chlorination rates revealed strong effects in the treatment with the simple saccharide addition that reached final and higher ${ }^{36} \mathrm{Cl}_{\text {org }}$ levels much faster than the other treatments (Figure 3). Hence, it seems that the most labile organic matter in the GMSC treatment was rapidly degraded and fueled a greater chlorination rate before being depleted, after which this treatment behaved like the other treatments with less labile OM. If these results are valid also for open “flow-through” systems in nature, with different types of OM sources being imported and exported continuously increased chlorination rates are to be expected whenever more labile OM is present.

The results appear to provide evidence against Hypothesis 3 outlined in the Introduction, stating that chlorination represents a way for microorganisms to access large complex organic matter by cutting it into smaller organic molecules. If chlorination primarily is a mechanism 
to break and access complex refractory SOM, high chlorination rates would be most important and selected for (by natural selection) in microbial communities in the treatments with the most refractory organic matter, i.e. in the aged original soil. If, on the other hand, chlorination is indirectly linked to overall microbial metabolism, the observed patterns in the two experiments I and II are expected, as addition of the more labile carbon likely stimulated general microbial metabolism. Thus, the finding that labile organic matter stimulated chlorination could simply indicate that chlorination processes are proportional to general microbial metabolism in soils, which in turn would support Hypothesis 1 or 2 in the Introduction, as the need for detoxifying reactive oxygen species and to inhibit competitors by allelopathy should increase with increasing microbial activity. In addition, the development over time in Experiment II indicates that an increased chlorination following glucose and maltose addition is a very fast process. Hence, our results may indicate that the ability to perform chlorination is an inherent metabolic capacity of any soil microbial community, and that chlorination is a general process along with Hypotheses 1 and 2, rather than being performed by fewer organisms requiring community changes from natural selection to become extensive. Similarly, Bengtsson et al. ${ }^{9}$ found that the genes for CPO is very widespread among microorganisms.

Because the results of this study strengthen Hypotheses 1 and 2 and weakens Hypotheses 3, it is of interest to examine the existing support for Hypothesis 3. It is clear that chlorination can lead to formation of chlorinated soil organic matter with widely different reactivity ${ }^{4,15,29}$. Biotic chlorination has been linked to organic matter decomposition because accumulation of $\mathrm{Cl}_{\text {org }}$ upon humification of plant material has been observed, along with the early findings that fungal chloroperoxidases can chlorinate lignin structures ${ }^{13,15}$. This is suggested to partly explain the high amount of organically bound chlorine, up to $29-100 \%$ of total chlorine in soils (observed in coniferous and deciduous soils, agricultural soils, peat soils and 
grassland $)^{30,31}$. There are also indications that the amount of $\mathrm{Cl}_{\text {org }}$ is positively correlated with SOM levels ${ }^{3}$. However, this evidence does not exclude that the reasons for chlorination are related with Hypotheses 1 and 2, and the amount of $\mathrm{Cl}_{\text {org }}$ observed in different soils does not necessarily reflect chlorination but could simply reflect how resistant to dechlorination or overall degradation the formed $\mathrm{Cl}_{\text {org }}$ are. Possibly, an input of large and complex organic matter to soils (e.g. lignin-rich wood) lead to formation of refractory $\mathrm{Cl}_{\text {org }}$ that accumulates and thereby the $\mathrm{Cl}_{\text {org }}$ levels become high. High levels of $\mathrm{Cl}_{\text {org }}$ can lead to assumptions of high net-chlorination rates, although gross chlorination and dechlorination rates may be much higher in environments with input of more labile organic matter and higher microbial activity even if overall $\mathrm{Cl}_{\text {org }}$ levels are low unless large amounts of refractory $\mathrm{Cl}_{\text {org }}$ accumulate. Net $\mathrm{Cl}_{\text {org }}$ formation rates can therefore to a large extent depend on the stability of the $\mathrm{Cl}_{\text {org }}$ formed, rather than on gross chlorination rates. In this way, Hypotheses 1 and 2, according to which chlorination should be positively correlated to and regulated as overall microbial metabolism, seem compatible with available observations of chlorination and $\mathrm{Cl}_{\text {org }}$ levels, including with recent findings of most rapid net accumulation of $\mathrm{Cl}_{\text {org }}$ in coniferous forest stands, compared to deciduous forest, by Montelius et al. ${ }^{19}$. However, it should be noted that the three outlined hypotheses are not mutually exclusive. They could all be valid and have different relative importance under different conditions, and needs more studies to be confirmed.

\section{Nitrate addition hampered chlorination}

The experimental addition of nitrate as a single factor, clearly hampered soil chlorination (Table 2). This is in line with a previous study on soil chlorination in which Johansson et al (2001) observed that addition of nitrogen (ammonium nitrate, $\mathrm{NH}_{4} \mathrm{NO}_{3}$ ) to soil samples led to lower amounts of $\mathrm{Cl}_{\text {org }}$ in soils ${ }^{1}$. In two fertilization $\left(\mathrm{NH}_{4} \mathrm{NO}_{3}\right)$ experiments, a hampering effect of nitrogen has been observed. Öberg et al (1996) observed a decreased net formation 
of $\mathrm{Cl}_{\text {org }}$ during decomposition of spruce needles in $\mathrm{N}$-fertilized plots and Svensson et al 2013 observed lower concentrations of $\mathrm{Cl}_{\text {org }}$ in $\mathrm{N}$-fertilized plots compared to control plots ${ }^{20,32}$. It has been suggested that this was due to different factors, such as alteration of the microbial community, or effects on the enzymes that are active in chlorination. The Johansson et al. (2001) study was followed by a soil core incubation study where no effects of nitrogen additions $\left(\mathrm{NH}_{4} \mathrm{NO}_{3}\right)$ were seen ${ }^{21}$. Recently another experimental study on chlorination and dechlorination in a forest soil provided additional indications that nitrogen $\left(\mathrm{NH}_{4} \mathrm{NO}_{3}\right)$ hampers chlorination ${ }^{16}$. Hence, considering the results from the present and the previous studies, most evidence indicate that increased levels of nitrogen, will inhibit chlorination in soils.

Soil microbial activity may be affected by nitrogen in various ways. It has been suggested that nitrogen can both enhance carbon sequestration and reduce soil respiration ${ }^{33,34}$ indicating that nitrogen may decrease soil microbial activity. There are also studies indicating that fungi and fungal activity is affected negatively by elevated soil nitrogen ${ }^{35,36}$. Hence, nitrogen additions could reduce chlorination rates in situations where fungal activity is associated with a significant share of the chlorination.

\section{Effects of chloride addition}

Addition of $\mathrm{Cl}^{-}$as a single factor yielded an increased chlorination. This is not surprising since chlorination requires $\mathrm{Cl}^{-}$. Soils are rarely considered to have a $\mathrm{Cl}^{-}$deficit, and thus $\mathrm{Cl}^{-}$ background levels are usually not seen as limiting for chlorination rates. There are however few studies on how chlorination rates are affected by $\mathrm{Cl}^{-}$levels. This study show that a higher level of $\mathrm{Cl}^{-}$did increase the chlorination rate in a soil were initial $\mathrm{Cl}^{-}$levels were normal for the soil type (i.e. not low). Hence, it is possible that chlorination rates can be influenced by changing pore water $\mathrm{Cl}^{-}$concentrations and ionic strength such as during dry or wet periods and in areas with anthropogenic $\mathrm{Cl}^{-}$additions to the soil, e.g. from road salt ${ }^{37,38,39}$. 


\section{Effects of the soil moisture content on chlorination}

Soil moisture is presumably important for soil $\mathrm{O}_{2}$ levels and a previous study indicated that chlorination is hampered under anoxia ${ }^{6}$. This is logical, as chlorination of organic matter is an oxidative process. Besides affecting the $\mathrm{O}_{2}$ regime, soil moisture can also affect the transport of pore water solutes and the availability of substrates for microbial cells. Increased soil moisture facilitating movement of water and solutes could therefore potentially stimulate microbial activity and chlorination, and counteract the effect of reduced $\mathrm{O}_{2}$ levels at higher water content. In this study, soil moisture alone had no clear main effect on chlorination in the current study. A change from 30 to $70 \%$ soil moisture may not have been large enough to affect chlorination, or the different impacts on $\mathrm{O}_{2}$ and substrate supply rates balanced each other leading to a negligible net effect. The results of the soil moisture treatment calls for additional work examining the influence of soil moisture levels on chlorination.

\section{Combined effects of multiple factors on chlorination}

Among the combinations of factors, there was a clear pattern: All combinations with C, enhanced chlorination relative to the control while the influence of all other treatments on chlorination showed less consistent patterns (Figure 2). Altogether, the change in soil moisture from 30 to $70 \%$ did not influence chlorination in itself, but the $\mathrm{W}+\mathrm{C}+$ treatment enhanced chlorination to the same level as $\mathrm{C}+$ alone (Figure 2, Table 2). Addition of labile organic matter apparently partly counteracted the inhibitory effects of nitrogen. This was observed for some of the combination treatments with $\mathrm{C}+$ and $\mathrm{N}+$ at day $60(\mathrm{~N}+\mathrm{C}, \mathrm{W}+\mathrm{N}+\mathrm{C}+$ and $\mathrm{W}+\mathrm{N}+\mathrm{Cl}+\mathrm{C}$ ), which clearly showed higher chlorination than the control (Figure 2). One possible explanation is that high availability of both labile organic matter and nitrate greatly stimulated the microbial activity by removing both carbon and nitrogen limitations. Importantly, all results from the two independent experiments showed that the treatments having the highest potential to stimulate microbial activity also in general stimulated the 
chlorination rates, and indicates that chlorination may be more strongly associated with general metabolic processes such as defense against reactive oxygen species or allelopathic interactions, than to the degradation of refractory organic matter. Obviously further verification is needed, but if correct, gross chlorination rates would be regulated in similar ways as soil microbial activity.

\section{CORRESPONDING AUTHOR}

*Corresponding Author: teresia.svensson@liu.se

\section{ACKNOWLEDGMENTS}

This study was supported by the Swedish Research Council (VR) and the Swedish Nuclear Fuel and Waste Management Company (SKB). We thank Susanne Karlsson, Monica Petersson, and Lena Lundman for invaluable practical assistance. We also thank Gunilla Öberg for contributing to preparatory work making this study possible, and are grateful for the comments by the anonymous reviewers and the editor that helped improve the text.

\section{Author Contributions}

The study was initiated by DB and planned by TS, DB, and MM. TS, HR, MM, MA, KR, and $\mathrm{Cl}$ performed most laboratory work. TS, DB, HR and $\AA \mathrm{D}$ analyzed the data. All authors contributed to the development of text.

\section{REFERENCES}

1. Johansson, E.; Ebenå, G.; Sandén, P.; Svensson, T.; Öberg, G., Organic and inorganic chlorine in Swedish spruce forest soil: influence of nitrogen. Geoderma 2001, 101, (3-4), 1-13.

2. Redon, P. O.; Jolivet, C.; Saby, N. P. A.; Abdelouas, A.; Thiry, Y., Occurrence of natural organic chlorine in soils for different land uses. Biogeochemistry 2013, 114, (1-3), 413-419.

3. Gustavsson, M.; Karlsson, S.; Öberg, G.; Sanden, P.; Svensson, T.; Valinia, S.; Thiry, Y.; Bastviken, D., Organic matter chlorination rates in different boreal soils: The role of soil organic matter content. Environ. Sci. Technol. 2012, 46, (3), 1504-1510. 
4. van Pee, K. H.; Unversucht, S., Biological dehalogenation and halogenation reactions. Chemosphere 2003, 52, (2), 299-312.

5. van Pee, K. H., Microbial synthesis of halometabolites. Archieves of microbiology 2001, 175, 250-258.

6. Bastviken, D.; Svensson, T.; Karlsson, S.; Sandén, P.; Öberg, G., Temperature sensitivity indicates that chlorination of organic matter in forest soil is primarily biotic Environmental Science and Technology 2009, 43, (10), 3569-3573.

7. Keppler, F.; Eiden, R.; Niedan, V.; Pracht, J.; Schöler, H., Halocarbons produced by natural oxidation processes during degradation of organic matter. Nature 2000, 403, (6767), 298-301.

8. Fahimi, I. J.; Keppler, F.; Scholer, H. F., Formation of chloroacetic acids from soil, humic acid and phenolic moieties. Chemosphere 2003, 52, (2), 513-520.

9. Bengtson, P.; Bastviken, D.; de Boer, W.; Öberg, G., Possible role of reactive chlorine in microbial antagonism and organic matter chlorination in terrestrial environments. Environmental Microbiology 2009, 11, (6), 1330-1339.

10. Hewson, W. D.; Hager, L. P., Biochemistry. Academic Press: 1979.

11. Monde, K.; Satoh, H.; Nakamura, M.; Tamura, M.; Takasugi, M., Organochlorine compounds from a terrestrial higher plant: Structures and origin of chlorinated orcinol derivatives from diseased bulbs of Lilium maximowiczii. Journal of Natural Products 1998, 61, (7), 913-921.

12. Bengtson, P.; Bastviken, D.; Öberg, G., Possible roles of reactive chlorine II: assessing biotic chlorination as a way for organisms to handle oxygen stress. Environmental Microbiology 2013, 15, (4), 991-1000.

13. Myneni, S., Formation of stable chlorinated hydrocarbons in weathering plant material. Science 2002, 295, (5557), 1039-1041.

14. Ortiz-Bermudez, P.; Hirth, K. C.; Srebotnik, E.; Hammel, K. E., Chlorination of lignin by ubiquitous fungi has a likely role in global organochlorine production. Proceedings Of The National Academy Of Sciences Of The United States Of America 2007, 104, (10), 3895-3900.

15. Ortiz-Bermúdez, P.; Srebotnik, E.; Hammel, K., Chlorination and cleavage of lignin structures by fungal chloroperoxidases. Appl. Environ. Microbiol. 2003, 69, (8), 5015-5018.

16. Montelius, M.; Svensson, T.; Lourino-Cabana, B.; Thiry, Y.; Bastviken, D., Chlorination and dechlorination rates in a forest soil - A combined modelling and experimental approach. Sci. of the Tot. Environ. 2016, 554-555, 203-210.

17. McCarty, P. L., Breathing with chlorinated solvents. Science 1997, 276, (5318), 1521-1522.

18. Leri, A. C.; Myneni, S. C. B., Organochlorine turnover in forest ecosystems: The missing link in the terrestrial chlorine cycle. Global biogeochemical cycles 2010, 24, (4).

19. Montelius, M.; Thiry, Y.; Marang, L.; Ranger, J.; Cornelis, J. T.; Svensson, T.; Bastviken, D., Experimental evidence of large changes in terrestrial chlorine cycling following altered tree species composition. Environmental Science and Technology 2015, 49, (8), 4921-4928. 
20. Öberg, G.; Nordlund, E.; Berg, B., In situ formation of organically bound halogens during decomposition of Norway spruce needles: effect of fertilization. Can. J. of For. Res. 1996, 26, (6), 1040-1048.

21. Bastviken, D.; Sandén, P.; Svensson, T.; Ståhlberg, C.; Magounakis, M.; Öberg, G., Chloride retention and release in a boreal forest soil - effects of soil water residence time and nitrogen and chloride loads. Environmental Science and Technology 2006, 40, 2977-2982.

22. Johansson, E.; Sandén, P.; Öberg, G., Spatial patterns of organic chlorine and chloride in Swedish forest soil. Chemosphere 2003, 52, (3), 391-397.

23. Bastviken, D.; Thomsen, F.; Svensson, T.; Karlsson, S.; Sandén, P.; Shaw, G.; Matucha, M.; Öberg, G., Chloride retention in forest soil by microbial uptake and by natural chlorination of organic matter. Geochimica et Cosmochimica Acta 2007, 71, (13), 3182-3192.

24. Asplund, G.; Grimvall, A.; Jonsson, S., Determination of the total and leachable amounts of organohalogens in soil. Chemosphere 1994, 28, (8), 1467-1475.

25. Laniewski, K.; Dahlen, J.; Boren, H.; Grimvall, A., Determination of group parameters for organically bound chlorine, bromine and iodine in precipitation. Chemosphere 1999, 38, (4), 771-782.

26. Horrocks, D.L., A new method of quench monitoring in liquid scintillation counting: The H number concept. Journal of Radioanalytical Chemistry. 1978. 43, (2), 489-521.

27. Pérez, J.; Muñoz-Dorado, J.; De La Rubia, T.; Martínez, J., Biodegradation and biological treatments of cellulose, hemicellulose and lignin: An overview. International Microbiology 2002, 5, (2), 53-63.

28. Brown, M. E.; Chang, M. C. Y., Exploring bacterial lignin degradation. Current Opinion in Chemical Biology 2014, 19, (1), 1-7.

29. Gribble, G., Naturally Occurring organohalogen compounds - a comprehensive update. Springer: Wien, 2010; Vol. 91.

30. Redon, P. O.; Abdelouas, A.; Bastviken, D.; Cecchini, S.; Nicolas, M.; Thiry, Y., Chloride and organic chlorine in forest soils: storage, residence times, and influence of ecological conditions. Environ. Sci. Technol. 2011, 45, (17), 7202-7208.

31. Bastviken, D.; Svensson, T.; Sandén, P.; Kylin, H. Chlorine cycling and the fate of ${ }^{36} \mathrm{Cl}$ in terrestrial environments; Svensk Kärnbränslehantering AB (SKB), Swedish Nuclear Fuel and Waste Management Co, 2013.

32. Svensson, T.; Högbom, L.; Johansson, K.; Sandén, P.; Ring, E., Effects of previous nitrogen addition on chlorine in forest soil, soil solution and biomass. Biogeochemistry 2013, 116, 313.

33. Frey, S. D.; Ollinger, S.; Nadelhoffer, K.; Bowden, R.; Brzostek, E.; Burton, A.; Caldwell, B. A.; Crow, S.; Goodale, C. L.; Grandy, A. S.; Finzi, A.; Kramer, M. G.; Lajtha, K.; LeMoine, J.; Martin, M.; McDowell, W. H.; Minocha, R.; Sadowsky, J. J.; Templer, P. H.; Wickings, K., Chronic nitrogen additions suppress decomposition and sequester soil carbon in temperate forests. Biogeochemistry 2014, 121, (2), 305-316. 
34. Lovett, G. M.; Arthur, M. A.; Weathers, K. C.; Fitzhugh, R. D.; Templer, P. H., Nitrogen addition increases carbon storage in soils, but not in trees, in an Eastern U.S. deciduous forest. Ecosystems 2013, 16, (6), 980-1001.

35. Högberg, M. N.; Högberg, P.; Myrold, D. D., Is microbial community composition in boreal forest soils determined by $\mathrm{pH}$, C-to-N ratio, the trees, or all three? Oecologia 2007, 150, (4), 590-601.

36. Wallenstein, M. D.; McNulty, S.; Fernandez, I. J.; Boggs, J.; Schlesinger, W. H., Nitrogen fertilization decreases forest soil fungal and bacterial biomass in three long-term experiments. Forest Ecol. Manag. 2006, 222, (1-3), 459-468.

37. Findlay, S.E.G.; Kelly, V. R.; Emerging indirect and long-term road salt effects on ecosystems. Annals of the New York Academy of Sciences. 2011, 1223, 58-68.

38. Snodgrass, J. W.; Moore, J.; Lev, S. M.; Casey, R. E.; Ownby, D. R.; Flora, R. F.; Izzo, G. Influence of modern stormwater management practices on transport of road salt to surface waters. 2017, 51 (8), 4165-4172.

39. Robinson, H. K.; Hasenmueller, E. A. Transport of road salt contamination in karst aquifers and soils over multiple timescales. 2017. 603-604, 94-108. 


\section{TABLES}

Table 1. The factorial design of Experiment I. $(-)$ means that there was no addition and $(+)$ means that there was an addition (see text regarding the treatments).

\begin{tabular}{|c|c|c|c|c|}
\hline Treatment & $\begin{array}{c}\mathbf{W} \\
\mathrm{H}_{2} \mathrm{O}\end{array}$ & $\frac{\mathbf{N}}{\mathrm{NaNO}_{3}}$ & $\begin{array}{c}\text { C } \\
\text { Glucose+Maltose }\end{array}$ & $\begin{array}{c}\text { Cl } \\
\mathrm{NaCl}\end{array}$ \\
\hline Control & - & - & - & - \\
\hline W & + & - & - & - \\
\hline $\mathrm{N}$ & - & + & - & - \\
\hline $\mathrm{Cl}$ & - & - & - & + \\
\hline $\mathrm{C}$ & - & - & + & - \\
\hline $\mathrm{W}+\mathrm{N}$ & + & + & - & - \\
\hline $\mathrm{W}+\mathrm{C}$ & + & - & + & - \\
\hline $\mathrm{N}+\mathrm{C}$ & - & + & + & - \\
\hline $\mathrm{W}+\mathrm{N}+\mathrm{C}$ & + & + & + & - \\
\hline $\mathrm{W}+\mathrm{Cl}$ & + & - & - & + \\
\hline $\mathrm{N}+\mathrm{Cl}$ & - & + & - & + \\
\hline $\mathrm{W}+\mathrm{N}+\mathrm{Cl}$ & + & + & - & + \\
\hline $\mathrm{Cl}+\mathrm{C}$ & - & - & + & + \\
\hline $\mathrm{W}+\mathrm{C}+\mathrm{Cl}$ & + & - & + & + \\
\hline $\mathrm{N}+\mathrm{Cl}+\mathrm{C}$ & - & + & + & + \\
\hline $\mathrm{W}+\mathrm{N}+\mathrm{Cl}+\mathrm{C}$ & + & + & + & + \\
\hline
\end{tabular}


Table 2. Mean chlorination rates in the single treatments (factors N; nitrate, Cl; chloride, W; soil moisture, C; carbon) in Experiment I. Numbers represent median (min-max) of rates since the experiment start and $n=3$. For variability, see figures where all replicates are shown.

\begin{tabular}{l|c|c} 
Treatment & $\begin{array}{c}\text { Day } 15 \\
\left(\mathrm{ng} \mathrm{Cl} \mathrm{gdm} \mathrm{dm}^{-1}\right)\end{array}$ & $\begin{array}{c}\text { Day } 60 \\
\left(\mathrm{ng} \mathrm{Cl} \mathrm{gdm}_{\mathrm{dm}}^{-1} \mathrm{~d}^{-1}\right)\end{array}$ \\
\hline Control & $19.8(14.2-21.1)$ & $10.0(9.9-10.0)$ \\
& & \\
$\mathrm{N}$ & $4.5(4.4-5.8)$ & $1.7(1.5-2.2)$ \\
$\mathrm{Cl}$ & $47.6(32.2-62.9)$ & $19.4(15.2-81.3)$ \\
$\mathrm{W}$ & $17.8(17.0-23.2)$ & $10.3(6.9-11.1)$ \\
$\mathrm{C}$ & $56.7(40.4-58.2)$ & $15.5(13.7-17.5)$
\end{tabular}




\section{FIGURES}

Figure 1. Chlorination rate in the control samples during the incubation period. Day 0 represents the starting point when the soil had regained the original water content after isotope addition which took two days of drying at room temperature (some chlorination occurred during this pre-incubation period which was similar for all treatments). $n=3$

Figure 2. Chlorination rate of incubated samples with different combination treatments. The dotted lines represent the chlorination rate (min to max) at day 15 and day 60, respectively in the control samples.

Figure 3. Chlorination rates in different carbon lability treatments in Experiment I (see text for details). The treatments were "Control” (no organic matter additions), SWD (sawdust from spruce wood added), SC (starch+cellulose added in equal proportions), and GMSC (glucose + maltose + starch + cellulose added in equal proportions). In all additions, the total organic matter added corresponded to $20 \%$ of the original organic matter content. The soil was incubated for 140 days and three replicates were taken out from the incubation setup each sampling day. All treatments were sampled at the same times but to avoid overlapping standard deviation bars the sampling time for different treatments were slightly shifted in the graph. 
FIGURE 1




FIGURE 2
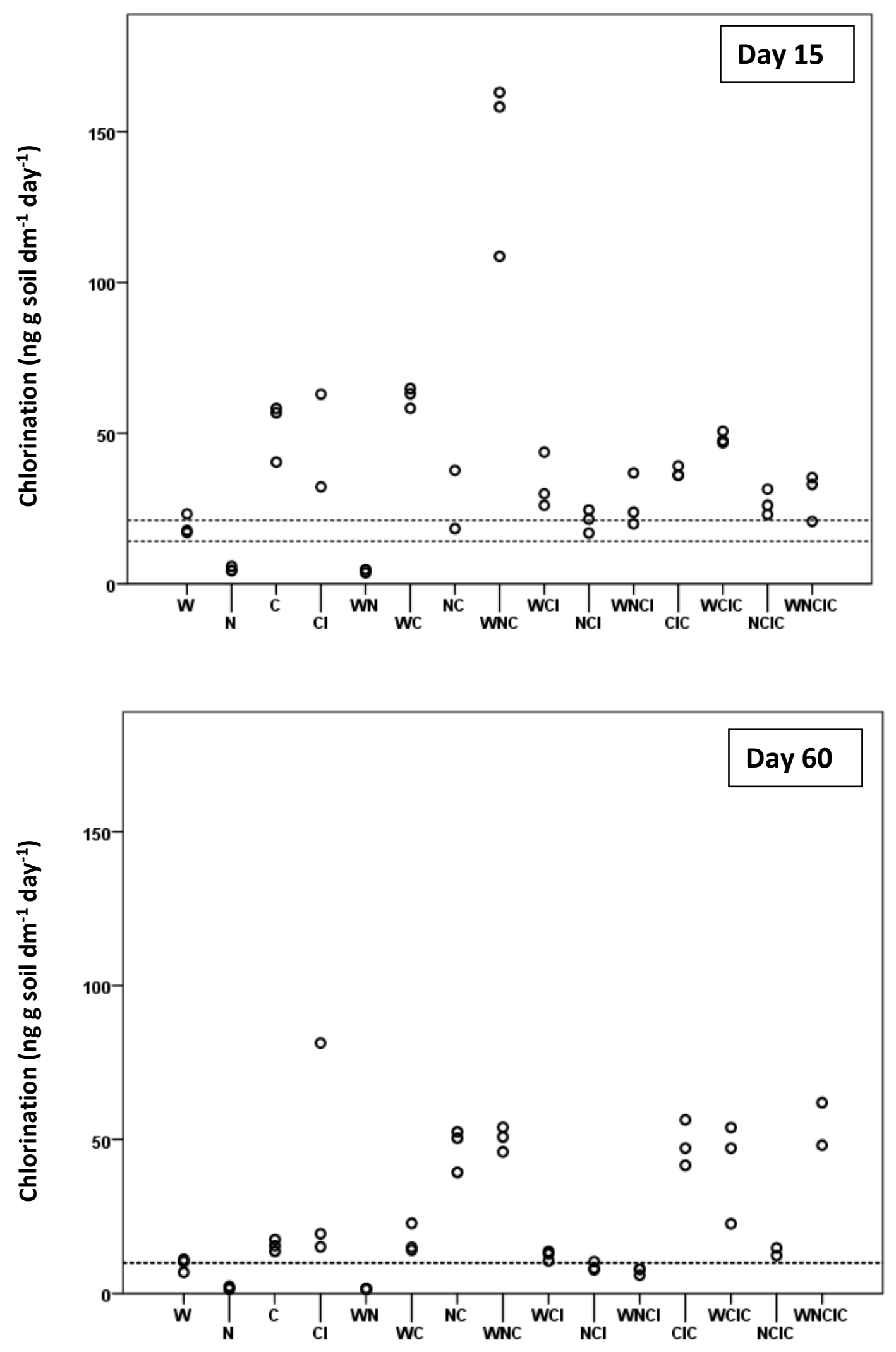

FIGURE 3 

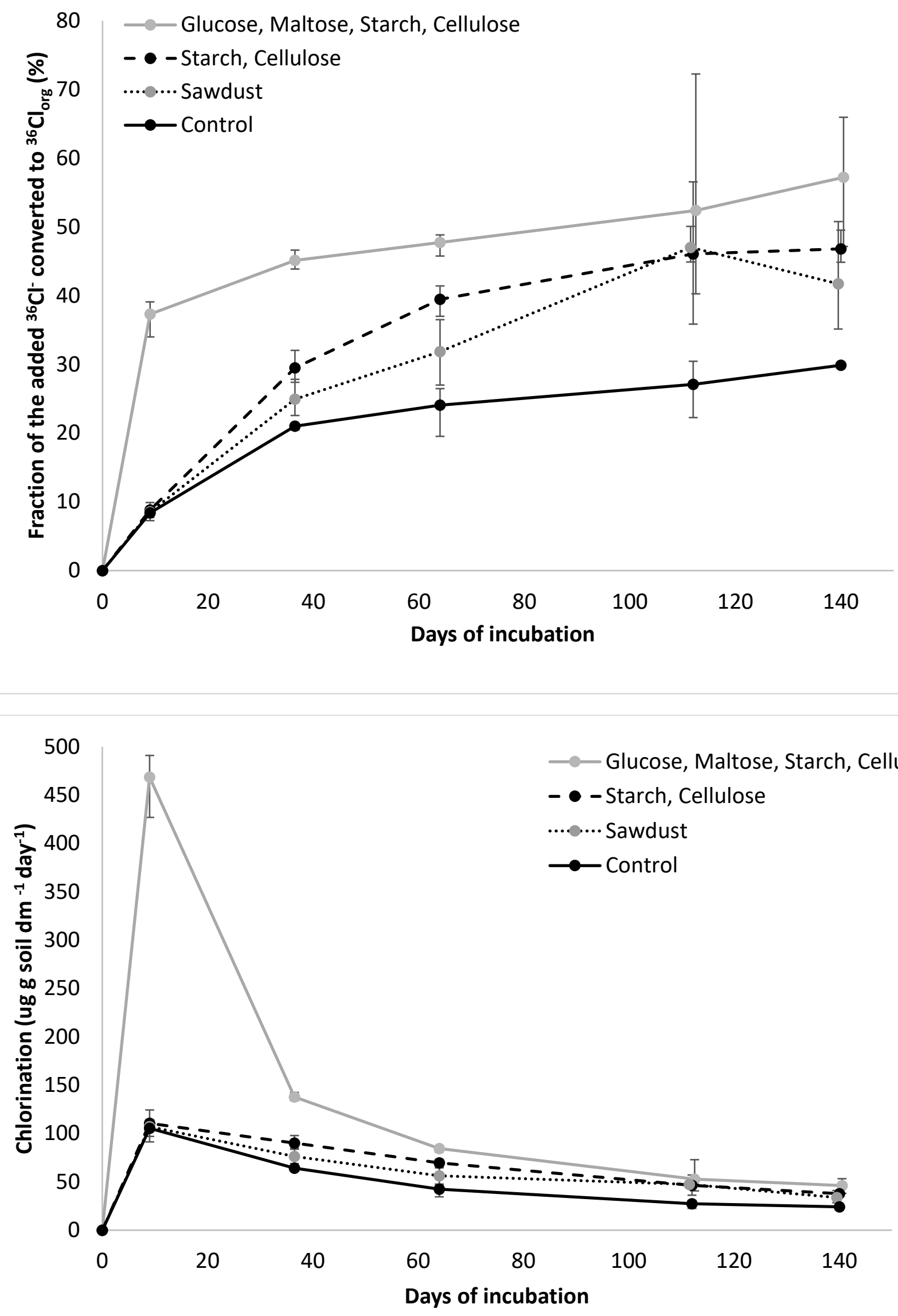